DOI: $10.19195 / 2084-5065.49 .7$

\title{
Ink protection of security documents
}

\author{
SALEH MANSOUR \\ Central Identification Bureau \\ Ministry of Interior, Beirut, Lebanon
}

\section{Introduction}

The term document security refers to protected valuable documents like travel documents (such as passports, visas, laissez passer...), IDs, driving licenses, banknotes, and all other valuable documents which are protected by a mixture of security features. These features are of many types which begins first from security paper, which includes embedded features like watermarks, fibers, planchettes, security threads, etc., and followed by inks, printing techniques, and additional security features, like optical variable ink, optical variable magnetic ink, MLI, CLI, TLI, SLI, etc. However, acquiring the skills for detecting genuine features, suspecting forgeries and counterfeit documents is a must not only for forensic document examiners, border control officers, immigration officials and prosecutors, public agents, but also for everyone who deals with such kinds of documents, namely IDs and banknotes.

This article will discuss the types of security documents, reasons for using fraudulent documents, printing techniques used in security documents, and main security features related to the inks used in security documents, supported by genuine and forged examples. 


\section{Types of security documents}

The main types of security documents are travel documents (passports, laissez passer, visas), identity documents such as identity cards, extract of civil status, residence permits, driving licenses, as well as banknotes. All these types are of very high value, because they are directly related to human identification, legal and financial rights. Moreover, these documents are related to the sovereignty of the state as they are delivered from legal governments. Furthermore, using forged or counterfeited travel or identity documents by an imposter represents a high risk to the country, it may be equal to a bomb in the hand of a terrorist, as far as they use such documents to disguise their illegal and destructive activities.

Even though there are other types of security documents like stamps, train tickets, cinema tickets, etc., the main question is for what reason the fraudulent documents are used.

\section{Reasons for using fraudulent documents}

Imposters use fraudulent documents for illegal reasons, including crossing borders illegally, human trafficking, smuggling of goods and migrants, committing crimes, terrorism and terrorist activities, and also for obtaining benefits and money. The imposters use another identity to escape from financial duties and responsibilities to avoid taxes, and to commit illegal acts without being responsible, as they transfer responsibility to the real person. This is the problem of identity theft, which is an extremely significant and complex problem, and also rapidly increasing. By a simple search using Google about "Identity theft" the result exceeds 150,000,000 hits, and that is a mere index of how huge such a phenomenon is. The question is, therefore, how to avoid it?

However, counting the global cost of fraudulent documents, and other related crimes such as identity theft, banknote counterfeiting, etc., at the individual level, state level, and world level, is unimaginable. Thousands of persons are living with the identity of others, profiting from social security payments, insurance, real estate ownership, and even bank 
accounts of the real holders' identities, without holding any responsibility which is still on the shoulders of the real individuals. ${ }^{1}$

The worst scenario becomes insupportable when the imposters use the identity of others for committing crimes and terrorism. This is a really very grave and highly sensitive global problem.

Raising the awareness of such a problem is a must and necessary, but not sufficient to avoid its consequences. Public civil service staff, the police, border control, customs, and other public servants, are directly involved in its prevention as well as taking all necessary measures to stop any fraudulent use of security documents. On the other hand, all the members of each society are also responsible for the prevention and fighting processes.

\section{Printing techniques used in security documents}

The printing techniques characteristics are general indications to differentiate between suspected and genuine documents as they include many security features. That does not mean these techniques are used only in security documents, as they are used also for commercial purposes.

There are four main printing techniques: offset lithography, letterpress, intaglio, and silkscreen which may be detected simply by the naked eye or by touch, as well as through a magnifying glass.

\subsection{Offset lithography}

Offset lithography is indirect printing, where the inked image, or text, is transferred from a plate to a rubber blanket and then to the printing surface. The concept behind this technique is the repulsion of oil and water, where the flat image carrier on which the image is to be printed obtains ink from ink rollers, while the non-printing areas attract a waterbased film keeping the non-printing areas ink free. ${ }^{2}$

The main characteristics of offset lithography are fine lines, even after being enlarged many times, the edges are still well-defined, untouch-

1 J. Hollegie, Basic Knowledge Document Recognition, Sdu, The Hague 2015, pp. $7-10$.

2 J. Hollegie, Basic Knowledge..., p. 118. 
able on surfaces where the ink absorbed by the substrate does not leave any touchable traces on the surface (Fig. 1). ${ }^{3}$

Different kinds of ink may be used in offset printing, but all of them are solid pastel colored ink, ultraviolet (UV) fluorescent visible and invisible ink, infrared visible and invisible fluorescent ink, thermal and photochromic ink, etc.

Micro-text could be printed by offset lithography in positive and in negative printing (Fig. 2).
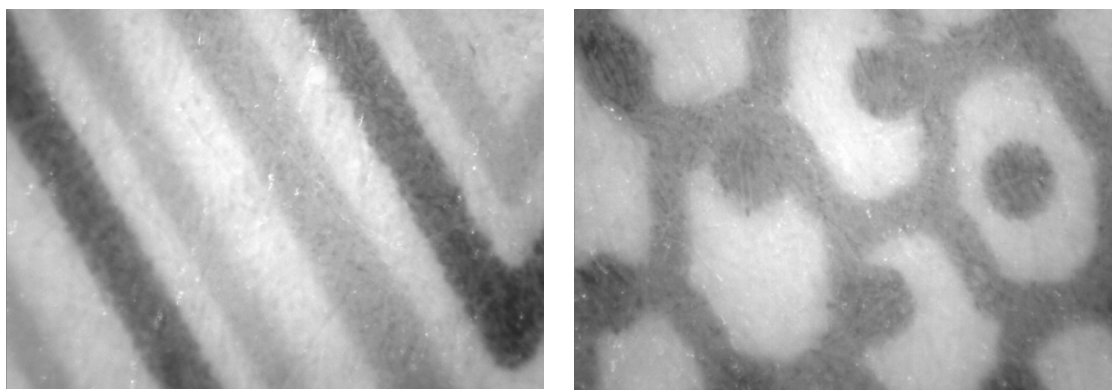

Figure 1. Offset colors are pastel soft and solid colors, as they are used for background printing; left: 20,000 Lebanese pounds; right: 1,000 Lebanese pounds ${ }^{4}$
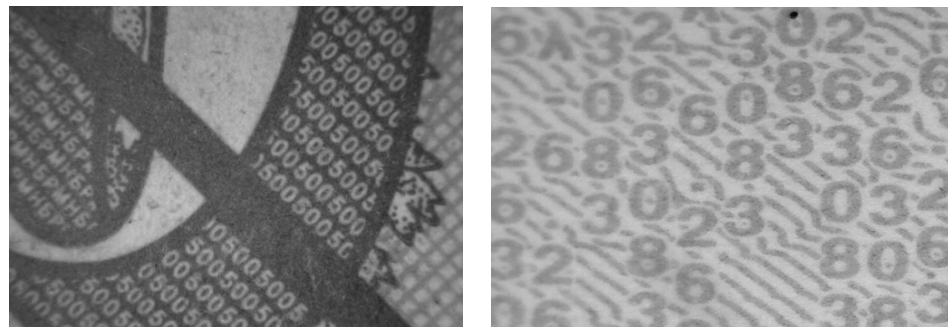

Figure 2. Offset printing always shows details, and micro-printing in negative and positive; left: Dino-Lite microscope image; right: passport specimen

${ }^{3}$ C.M. Borota, "Printing techniques used to secure border crossing documents", International Journal of Criminal Investigation 2, 2012, no. 1, p. 33.

${ }^{4}$ For information about the source of illustrations see the list of illustrations at the end of the article. For other examples of all the printing techniques discussed in this article see also Regula Forensics, https://regulaforensics.com/en/knowledge-hub/glossarydocuments/ (accessed: 22.04.2018) and https://regulaforensics.com/en/knowledge-hub/ glossary-banknotes/ (accessed: 22.04.2018).

Nowa Kodyfikacja Prawa Karnego 49, 2018

(C) for this edition by CNS 


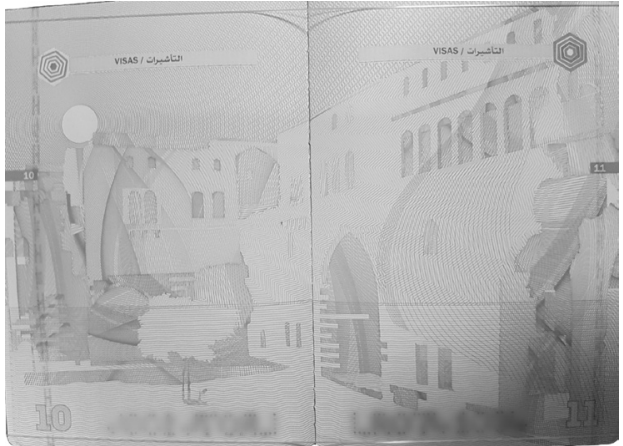

Figure 3. Special unique security pattern printed in offset, Lebanese biometric passport

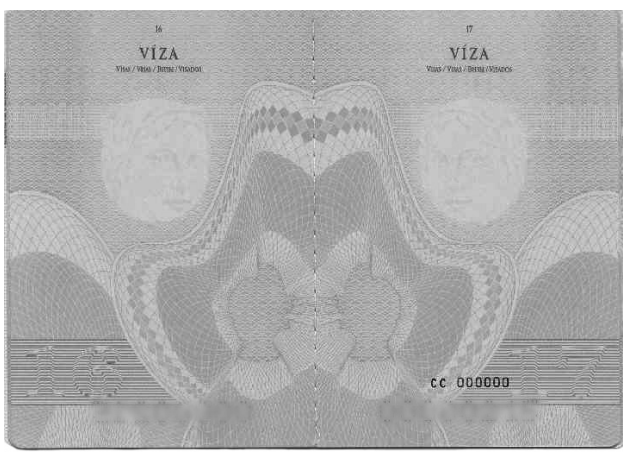

Figure 4. Guilloche and rainbow printing/IRIS

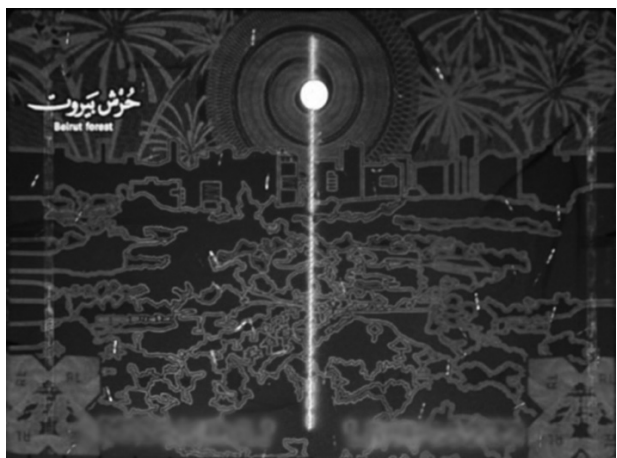

Figure 5. Lebanese biometric passport - invisible fluorescent ultraviolet ink, rainbow printing/IRIS 
The security features which are printed by offset printing are numerous and of high quality to be forged of imitated, as shown in the inner pages of passports and banknotes for example, security patterns and guilloche (Fig. 3 and 4).

Offset printing is the principal technique to apply rainbow printing, which is the smooth transition of colors of normal (daylight) inks and UV fluorescent inks (Fig. 4 and 5).

\subsubsection{Infacio ${ }^{\circledR}$}

Infacio ${ }^{\circledR}$ is a multi-level, full color security feature (Giesecke \& Devrient $\mathrm{GmbH}) .{ }^{5}$ It includes a combination of different wavelength fluorescent inks, longwave UV light and special shortwave UV light, which allows the printing inks to fluoresce in different colors according to the wavelength of the UV light used. The biodata page is reprinted on an extra page using invisible fluorescent ink, which makes any forging in the principal biodata page easily detectable, and verified by comparing it with the hidden information of the extra biodata page. This makes any forging attempt of the biodata page extremely difficult (Fig. 6).

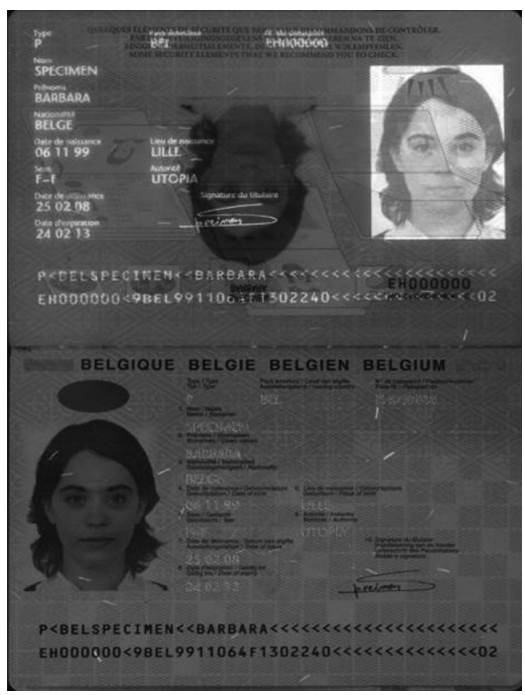

Figure 6. Infacio ${ }^{\circledR}$

5 J. Hollegie, Basic Knowledge..., p. 159; https://www.gi-de.com (accessed: 28.02.2019).

Nowa Kodyfikacja Prawa Karnego 49, 2018

(C) for this edition by CNS 


\subsubsection{The see-through register}

The see-through register is a very efficient security feature which is printed by the offset technique (Fig. 7).
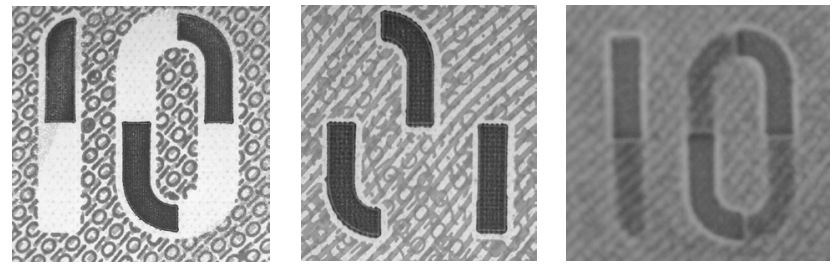

Figure 7. See-through register - 10 Rufiyaa, Maldives

The UV multicolor ink (visible and invisible) printed in the offset technique is widely-used in new passports and other security documents like IDs and driving licenses (Fig. 5).

\subsubsection{Photochromic ink}

Photochromic ink is a special type of UV fluorescent ink which contains a memory, after its exposure it reacts by shining, and still shining after this exposure in daylight. ${ }^{6}$ It is a high security feature, easily detectable and very difficult to forge (Fig. 8).
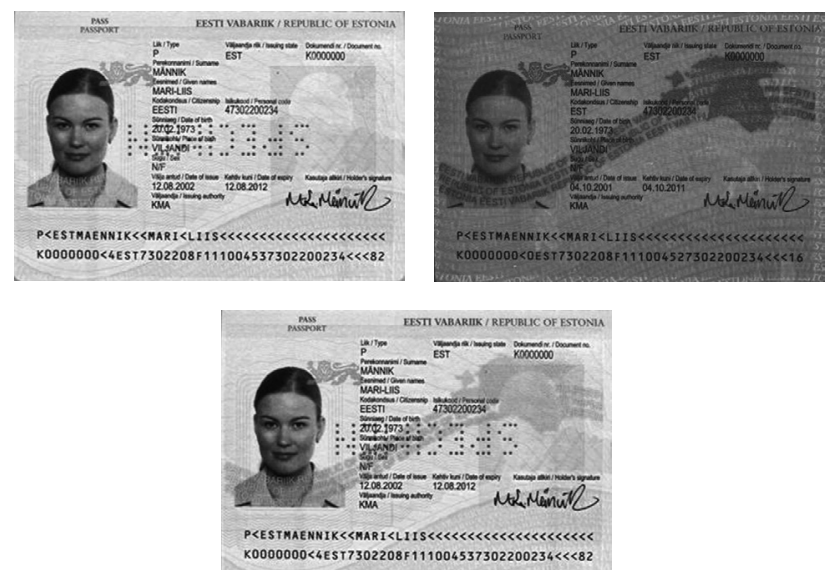

Figure 8. Photochromic ink

${ }^{6}$ J. Hollegie, Inkten Presentation, Team Identity Fraud, Amsterdam 2018.

Nowa Kodyfikacja Prawa Karnego 49, 2018

(C) for this edition by CNS 


\subsubsection{IR-fluorescent ink}

IR-fluorescent ink may be colored or colorless. This type of ink glows white when exposed to visible infrared. It is a high security feature, and needs special devices to be detected (Fig. 9). ${ }^{7}$

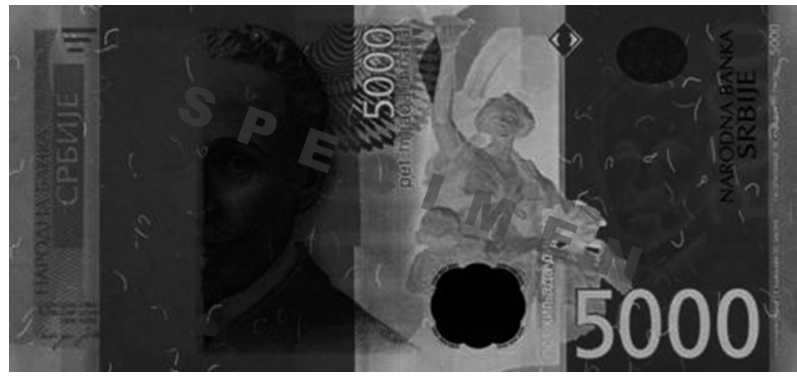

Figure 9. IR-fluorescent ink - 5,000 Serbian Dinar when exposed to infrared light

\subsubsection{Hidden multi-color}

A hidden multi-color image is printed by offset lithography and embossed by the intaglio technique, it is a highly-secure feature regarding how complex and difficult it is to be imitated (Fig. 10).
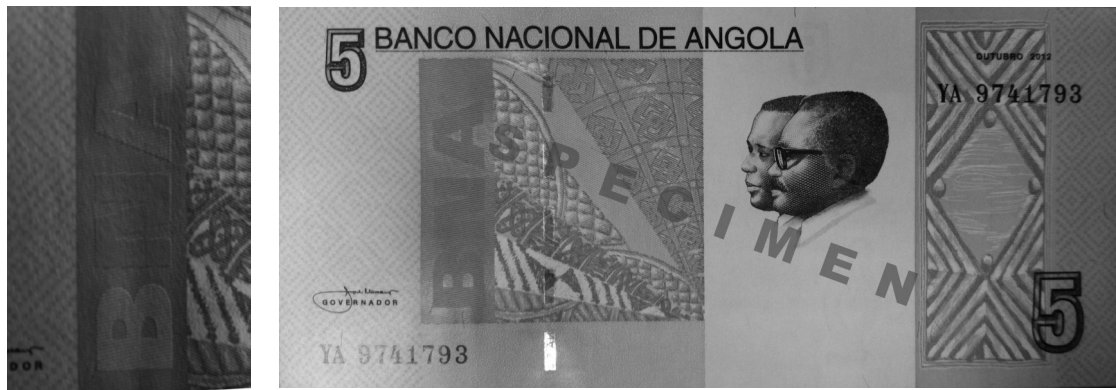

Figure 10. Hidden multi-color

7 Regula Forensics, https://regulaforensics.com/en/knowledge-hub/glossary-banknotes/ (accessed: 22.04.2018).

Nowa Kodyfikacja Prawa Karnego 49, 2018

(C) for this edition by $\mathrm{CNS}$ 


\subsubsection{Fugitive inks}

Fugitive inks are anti-forgery inks, sensitive to erasure, water, and chemicals, and they show any use of such solvents (Fig. 11). ${ }^{8}$
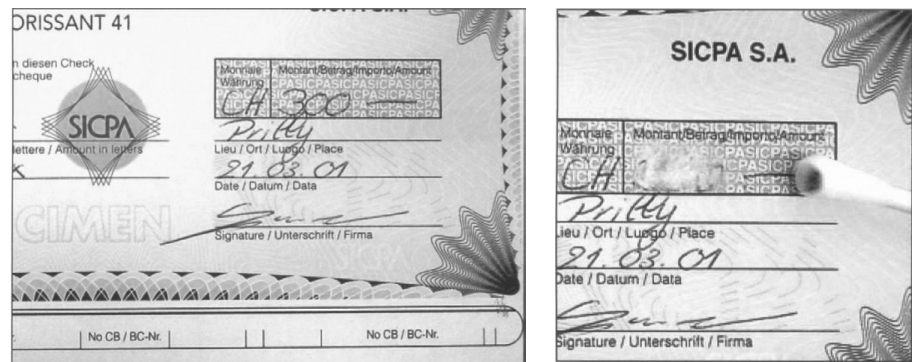

Figure 11. Fugitive ink

\subsubsection{Anti-Stokes inks}

Anti-Stokes inks are highly-secure inks, invisible under white light, and they glow in green under IR light, which can also be detected by special devices (Fig. 12).
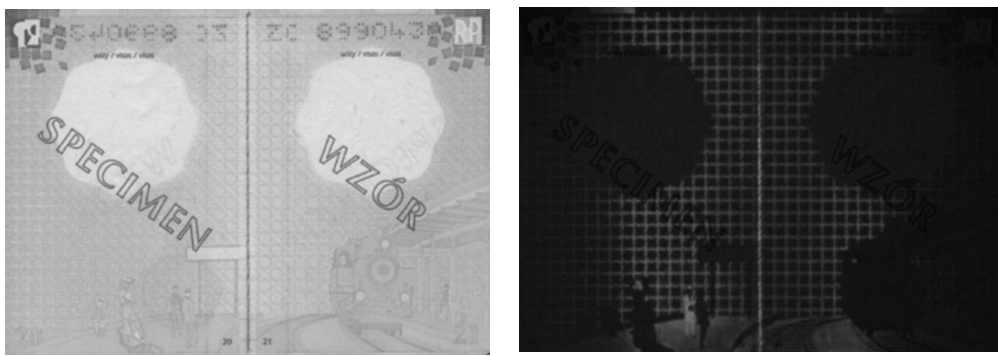

Figure 12. Anti-Stokes ink, Poland, official passport when exposed to infrared light

\subsubsection{Offset lithography forgery examples}

The main method for imitating offset lithography is by inkjet, whereas another technique like toner printing may also be used, which makes the verification process easier (Fig. 13-16). ${ }^{9}$

8 See also: J. Hollegie, Basic Knowledge..., p. 168; J. Hollegie, Inkten Presentation.

9 See also: J. Hollegie, Basic Knowledge..., p. 122.

Nowa Kodyfikacja Prawa Karnego 49, 2018

(C) for this edition by CNS 

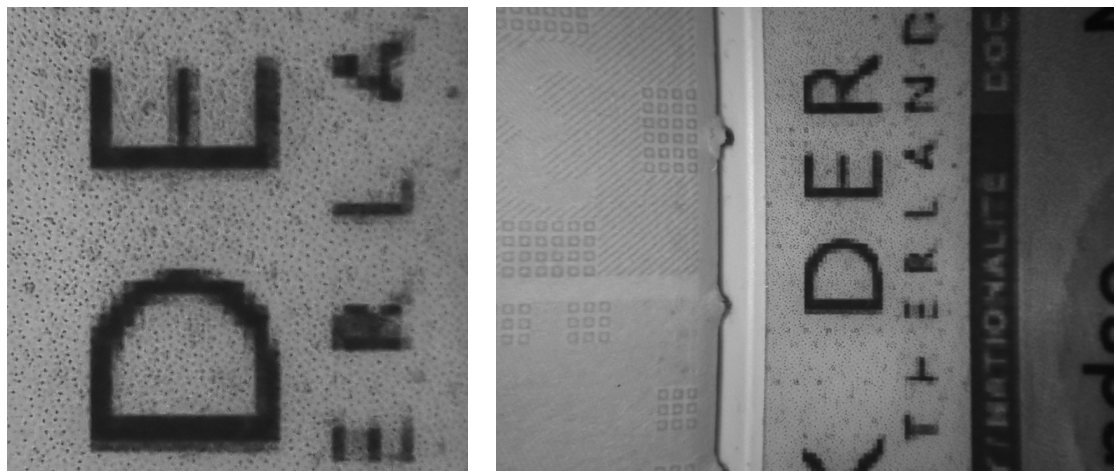

Figure 13. Forgery example.

Dutch passport biodata page — inkjet background. Offset imitation
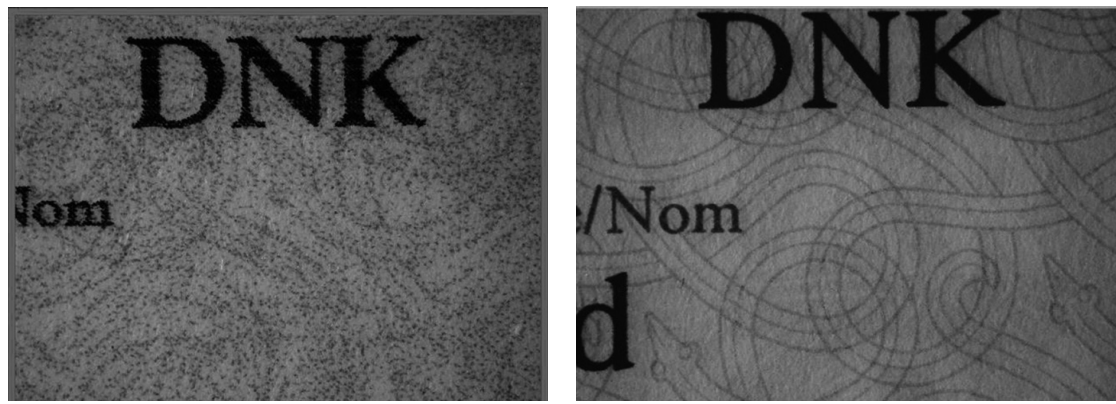

Figure 14. Forging example.

Danish passport biodata page - inkjet background. Offset imitation

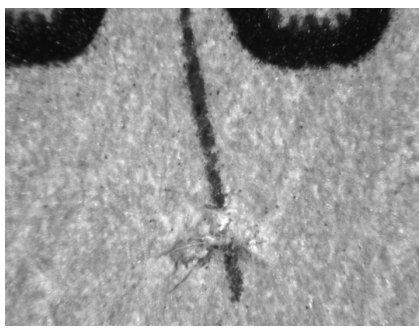

All inkjet printing:

— background

- serial number

- fibers

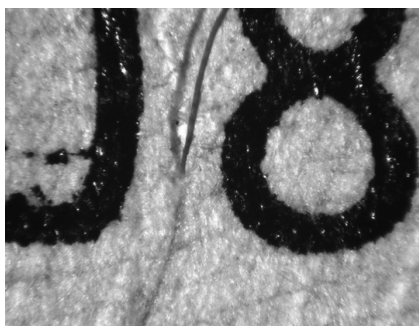

Background - offset

Serial number: Letterpress

Real fibers

Figure 15. Forgery example. Syrian passport extension sticker

Nowa Kodyfikacja Prawa Karnego 49, 2018

(C) for this edition by CNS 


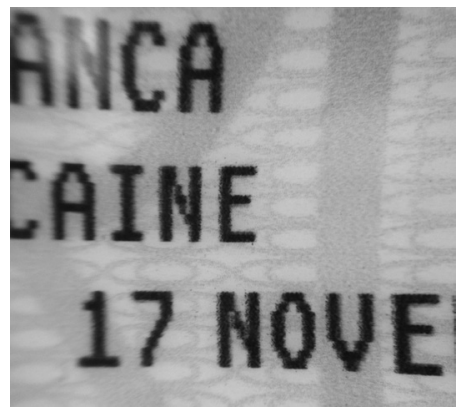

Figure 16. Forgery example. France - residence permit card, inkjet background. Offset imitation

\subsection{Intaglio}

The word intaglio has two meanings, which are intaglio inks, and the intaglio printing technique.

Intaglio ink is an expensive security ink, and it is extremely hard to be imitated. Whereas the intaglio printing technique is where the image is incised into the surface and the sunken area holds the ink, intaglio ink or other kinds of inks like optical variable ink may be used.

The intaglio printing method is used in the majority of security documents such as banknotes, passports and visas worldwide. It is old technology for the production of security prints. It is direct printing which needs a plate engraved by a motif pattern, text and/or image. The ink is applied on the printing plate, the redundant ink has to be removed from the raised non-printing area, and then transferred directly onto the substrate. ${ }^{10}$

A small amount of the thick intaglio ink is absorbed by the substrate, the incised line or sunken area holds the ink, whereas the majority, which is about $80 \%$, is still on the surface constituting a thick layer of ink and line structure with variable depth and width (tactile). The intaglio may be checked in a very easy way by the naked eye and by touch, and it does not require any sophisticated instruments. The other main characteristic of intaglio is feathering or frayed edges resulting from the printing process due to the thickness of the ink (Fig. 17, 19). ${ }^{11}$

10 M. Funk et al., "Intaglio quality measurement", Optical Document Security Conference, San Francisco, 10-12 February 2016, p. 1.

11 Ibid., p. 3.; C.M. Borota, op. cit., p. 35. 


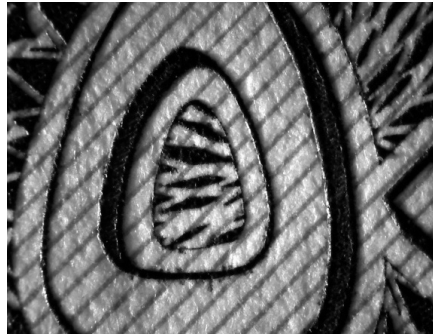

Figure 17. Intaglio:

(50,000 Lebanese banknote) feathering, relief, Orlof,

negative micro-text

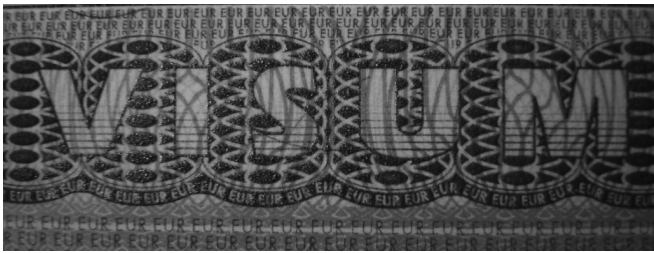

Figure 18. Schengen visa sticker: feathering, relief, Orlof, negative micro-text

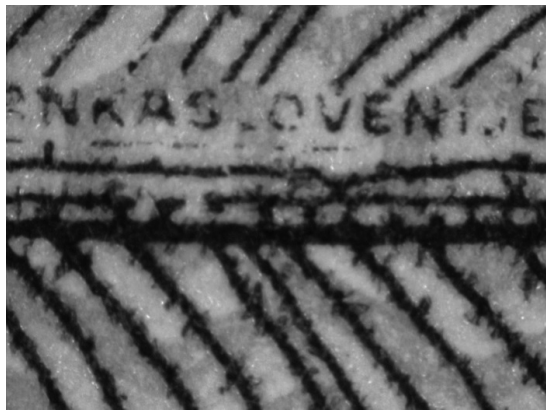

Figure 19. Intaglio: feathering

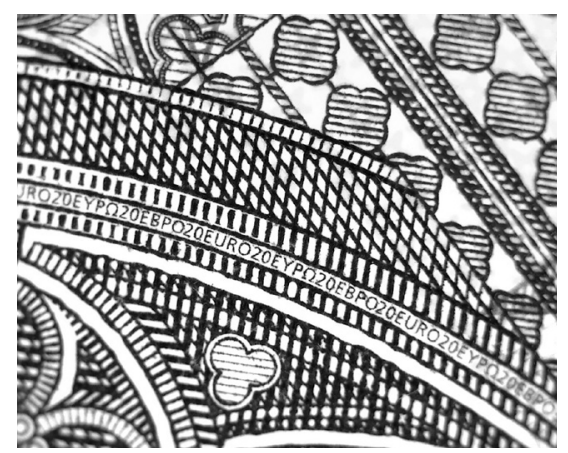

Figure 21. Intaglio:

(20 Euro banknote) feathering, relief, Orlof, positive micro-text

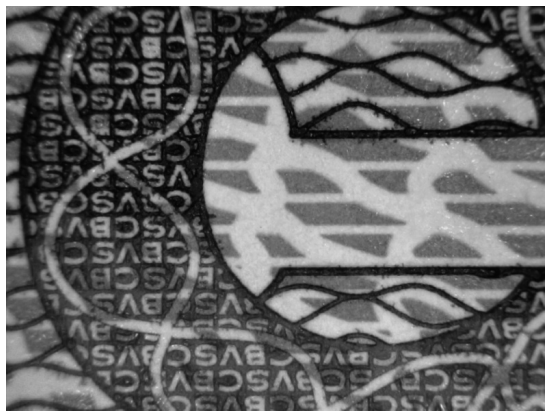

Figure 20. Intaglio: micro-text negative printing

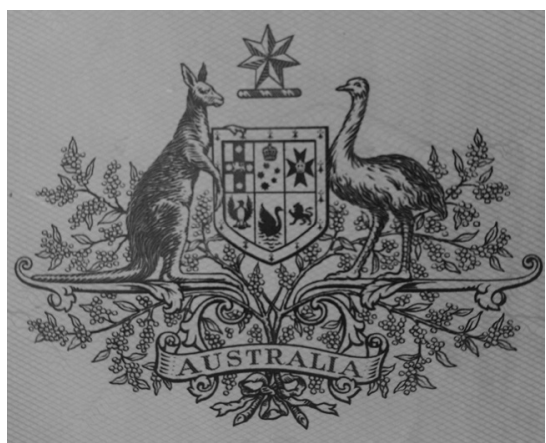

Figure 22. Intaglio: Australian passport, Orlof 
Intaglio inks are of solid colors, and the transmission between colors is direct and sharp, which is known as the Orlof effect. Intaglio ink might contain some security features like UV fluorescent ink, IR-fluorescent ink, infrared metameric ink, magnetic ink, and so on (Fig. 21, 22).

Moreover, the micro-text is widely used in intaglio printing in both positive and negative forms. The latent image technique is used by intaglio printing to facilitate the checking process and to verify the genuine documents printed from engraved plates and the photolithographic reproductions of the counterfeiter (Fig. 18, 20, 23, 24). ${ }^{12}$

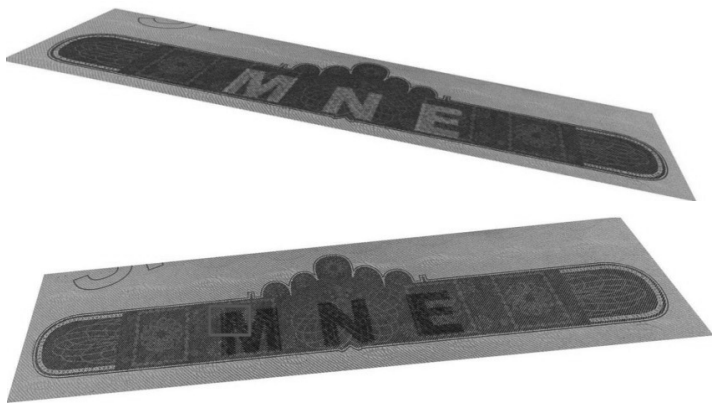

Figure 23. Montenegro official passport. Latent image KIPP, intaglio printing

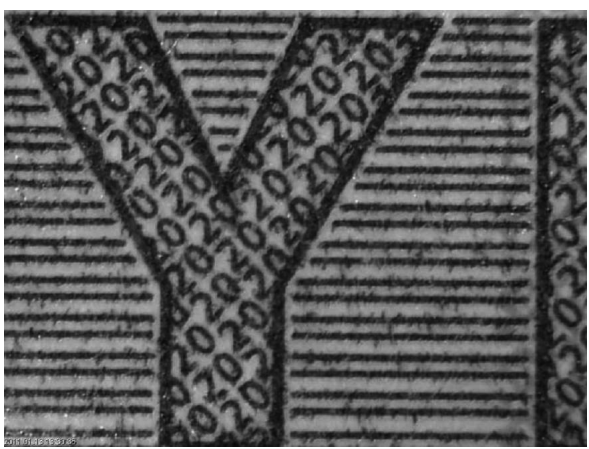

Figure 24. Intaglio: micro-text, positive printing

12 R.A. Huber, "The latent image and its role in document security", Canadian Society of Forensic Science Journal 10, 1977, no. 4, pp. 127-134 ; see also J. Hollegie, Basic Knowledge..., pp. 127-128. 


\subsubsection{Infrared metameric ink}

The infrared metameric ink type shows similar spectral properties under normal light, and differences in infrared spectrum $(870 \mathrm{~nm})$, inks either absorb or reflect IR light.
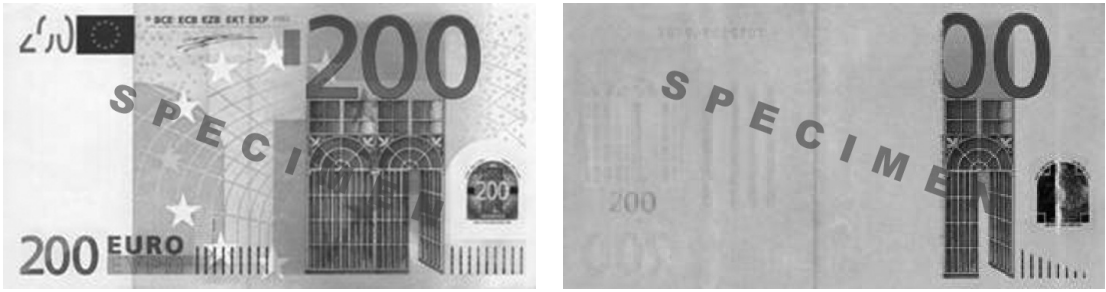

Figure 25. IR metameric ink — intaglio printing when exposed to infrared light

\subsubsection{Magnetic inks}

It contains ferromagnetic components, and can be added to many kinds of ink of any color and even colorless varnishes. The magnetic ink can be identified by special magnetic sensors or visualized by special devices. ${ }^{13}$

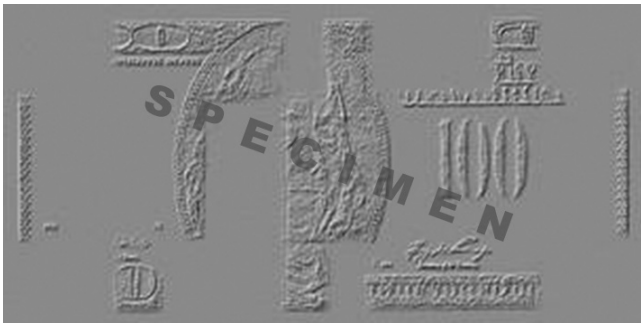

Figure 26. Magnetic inks — 100 USA Dollar, 2006

\subsubsection{Forgery examples of intaglio}

Intaglio inks are very expensive and difficult to acquire by forgers, so they use alternative inks from that of intaglio, which are still very far from the clear features of the genuine ink, and that makes the verification process easier, as shown in the figures (Fig. 27-30).

13 Regula Forensics, https://regulaforensics.com/en/knowledge-hub/glossary-banknotes/ (accessed: 22.04.2018). 


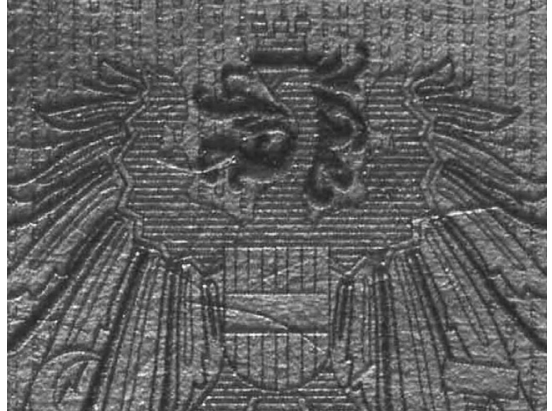

Figure 27. Intaglio Austrian passport

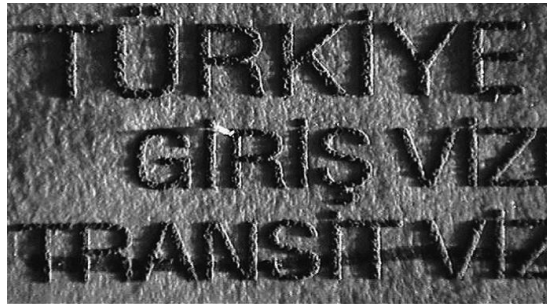

Figure 29. Intaglio Turkish transit visa sticker

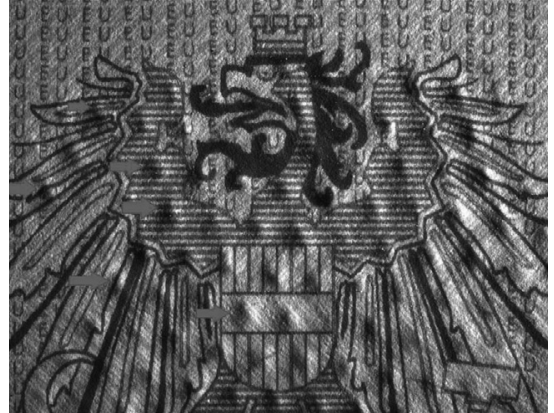

Figure 28. Intaglio imitation

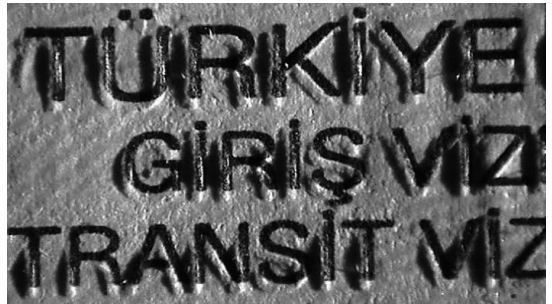

Figure 30. Intaglio imitation

\subsection{Letterpress printing}

This is the oldest type of printing technique in general, and also called relief printing, and typographic printing. It is used in security documents for the printing of serial numbers. The motif (number, letter, or image) of the raised surface is inked and impressed against the substrate, exactly like old-fashioned typewriters.

The impressing pressure results in some major characteristics of letterpress printing, which are beaded edges, an embossing effect, and printing interruptions, which makes the verification process quite easy. ${ }^{14}$

However, the embossing effect on the backside depends on two factors, which are the type of the substrate, and the force of the pressure exerted. ${ }^{15}$

14 C.M. Borota, op. cit., p. 33.

15 J. Hollegie, Basic Knowledge..., pp. 137-138. 
Different kinds of ink may be used in letterpress printing, like black and colored ink, bleeding ink, which is characterized by a red color on the edges of the printing motif and on the rear side, UV visible and invisible fluorescent ink, IR visible and invisible ink, magnetic ink, as well as multi-color ink, which has a unique combination of letters and numbers with the unique addition of UV, IR, and magnetic inks, and which contains encoded information in serial numbers: year of issue, series, issuing bank, factory, etc. ${ }^{16}$

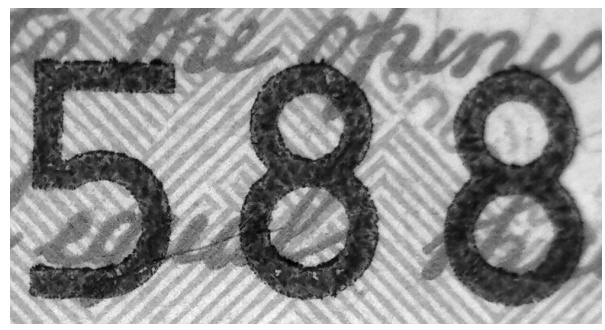

Figure 31. Letterpress - beaded edges, printing interruptions

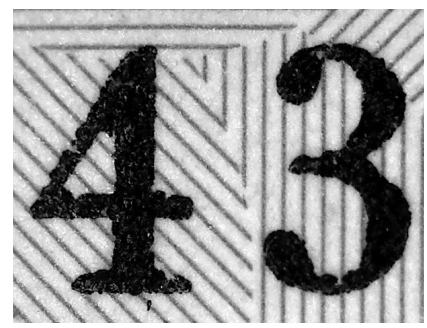

Figure 32. Letterpress 5,000 Lebanese pounds. Beaded edges, printing interruptions

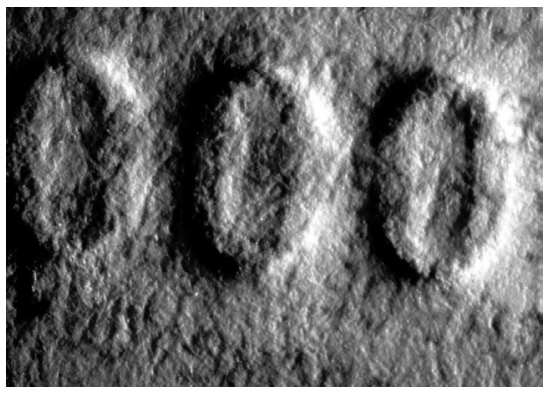

Figure 33. Letterpress - embossing effect on the rear side
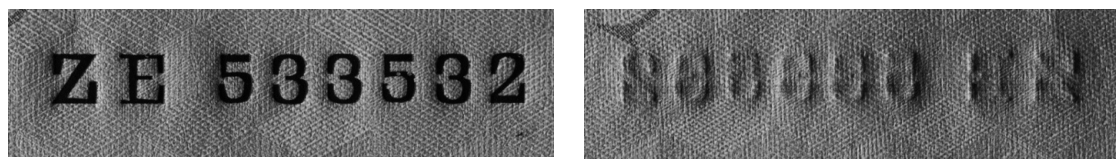

Figure 34. Letterpress: Hungarian passport, bleeding ink

16 Ibid.

Nowa Kodyfikacja Prawa Karnego 49, 2018

(C) for this edition by CNS 


\subsubsection{Multi-colored serial number}

This is a high-security feature usually printed by letterpress, and this includes a unique combination of letters and numbers. Other kinds of inks can be used, such as UV fluorescent visible and invisible ink, IR visible and invisible fluorescent ink, thermal, magnetic, and photochromic ink, etc.

Moreover, special information may be encoded in serial numbers which become a unique identification of the concerned secure document, such as year of issue, series, issuing establishment, a factory, the face value, etc. ${ }^{17}$

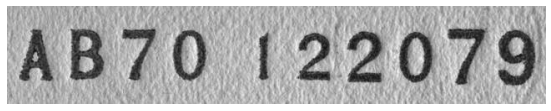

Figure 35. Multi-colored serial number

\subsubsection{Letterpress forged example}

Forgers usually use one printing technique for either background, which is supposed to be offset printing, and the serial number, which is supposed in the majority of cases to be letterpress.

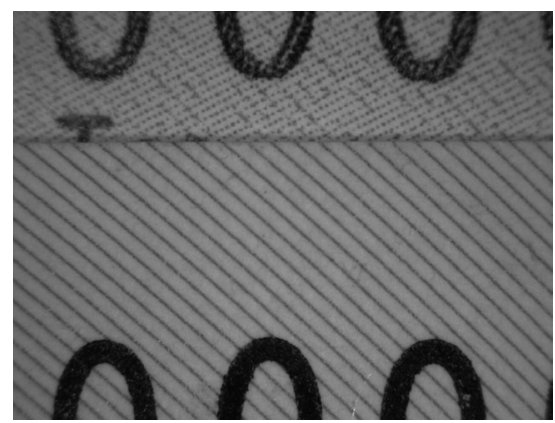

Figure 36. Letterpress - forged example

(inkjet V/S letterpress and offset);

Dino-Lite microscope image

17 Regula Forensics, https://regulaforensics.com/en/knowledge-hub/glossary-banknotes/ (accessed: 22.04.2018).

Nowa Kodyfikacja Prawa Karnego 49, 2018

(C) for this edition by CNS 


\subsection{Silkscreen}

Silkscreen, also called serigraphy, is a process in which an ink-blocking stencil is applied to a screen, allowing ink that is wiped across the screen to selectively pass through to the printing surface. Before the development of synthetic materials, silk was used as the screen material, giving this process the name silkscreen. The ink is spread onto the substrate by rubbing, rolling, or spraying paint or ink through the cut out areas. It is a very popular printing technique, mostly used for printing designs onto products.

The main characteristics of silkscreen printing are Tooth Edges of the printing area, and the thickness of the ink layer as the majority of it remains on the surface. ${ }^{18}$

However, the inks used in silkscreen printing for security documents are numerous, among them optical variable ink (OVI), optical variable magnetic ink (OVMI), iridescent ink, photochromic ink, magnetic ink, metallic ink and so on. ${ }^{19}$
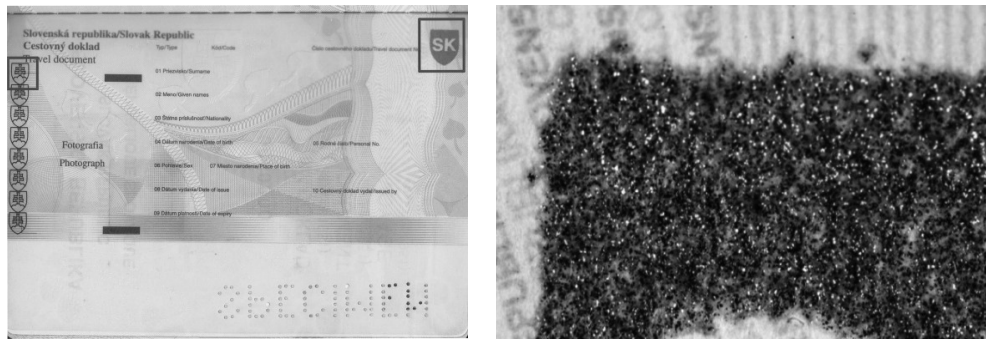

Figure 37. Silkscreen printing — tooth edges, Slovakia, travel document
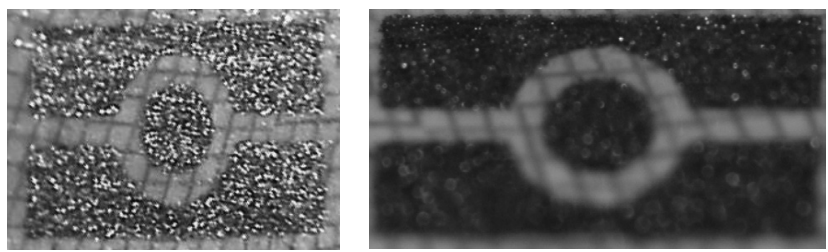

Figure 38. Silkscreen printing — new Lebanese passport — OVI

18 C.M. Borota, op. cit., p. 35.

19 J. Hollegie, Basic Knowledge..., pp. 142-143. 


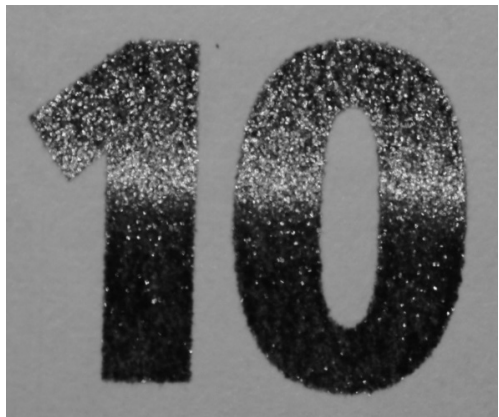

Figure 39. SPARK, OVMI silkscreen printing
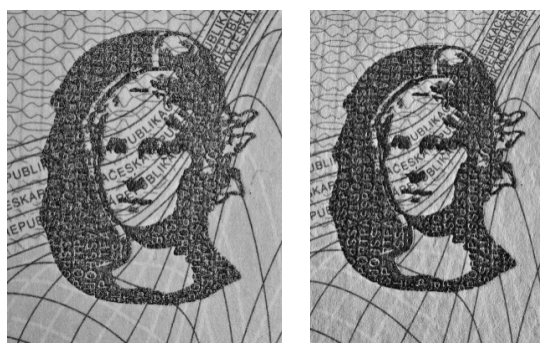

Figure 40. OVI silkscreen printing Czech passport

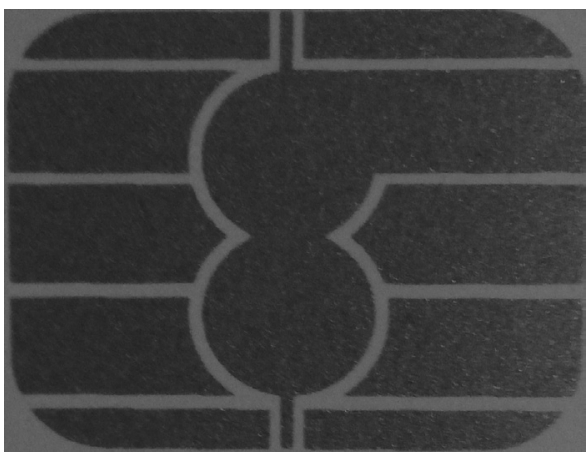

Figure 41. Conductive ink - silkscreen printing 


\subsubsection{Metameric inks pair}

The principle of metameric ink is that it looks similar in one type of illumination, and shows a noticeable difference in another type of light, a very secure feature against forgery, as it is easy for forgers to find a similar color on the market, but very hard for them to find the dual effect of a metameric ink pair, where the same unified color in daylight for example, gives two colors in a different light source. ${ }^{20}$

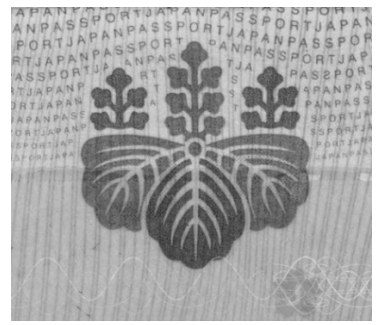

White light

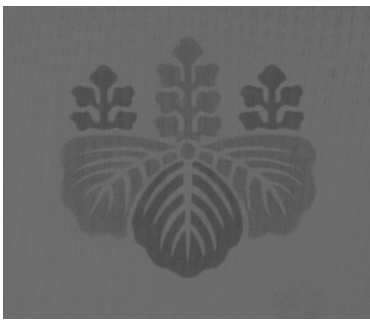

Orange light filter

Figure 42. Metameric inks pair — Japanese passport

\subsubsection{Thermal inks}

This type of ink changes its color when exposed to heat or either when it has another color, becomes visualized or decolorized.
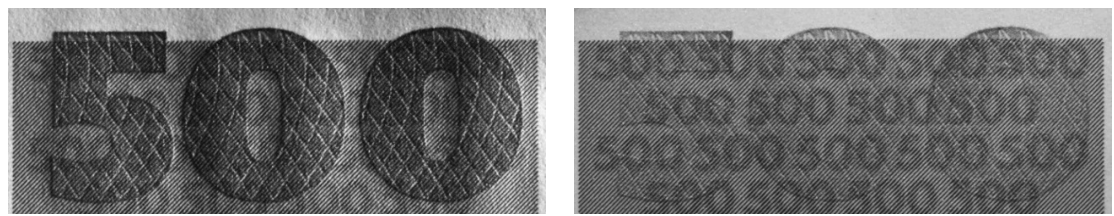

Figure 43. Thermal ink - 500 Latvian Lats, 2008

\subsubsection{Metallic inks}

Metallic inks contain metallic pigments of bronze or aluminum, and create a surface with a metal glow, a secure and anti-copy ink, as it shows totally different colors when copied.

20 Ibid., p. 190.

Nowa Kodyfikacja Prawa Karnego 49, 2018

(C) for this edition by $\mathrm{CNS}$ 


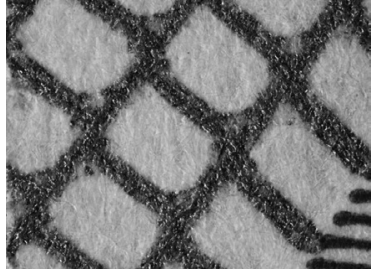

Figure 44. Metallic ink

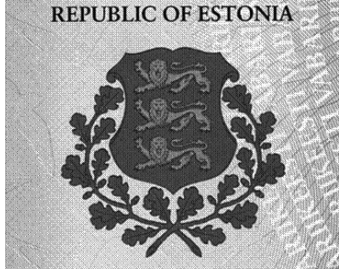

Figure 45. Metallic inks Estonian passport

\subsubsection{Conductive inks/electrographic inks}

These inks contain ferromagnetic components, and can be added to many kinds of ink of any color and even colorless varnishes. The magnetic ink can be identified by special magnetic sensors or visualized by special devices. $^{21}$

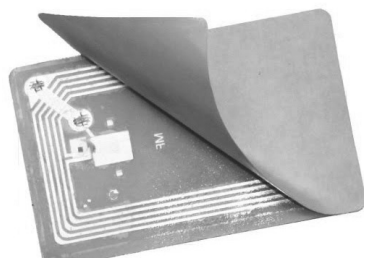

Figure 46. Conductive ink chip antenna

\subsubsection{Thermochromic inks}

Thermochromic inks change color or become invisible by heating to $27^{\circ}-35^{\circ} \mathrm{C}$, and reappear when the temperature drops.
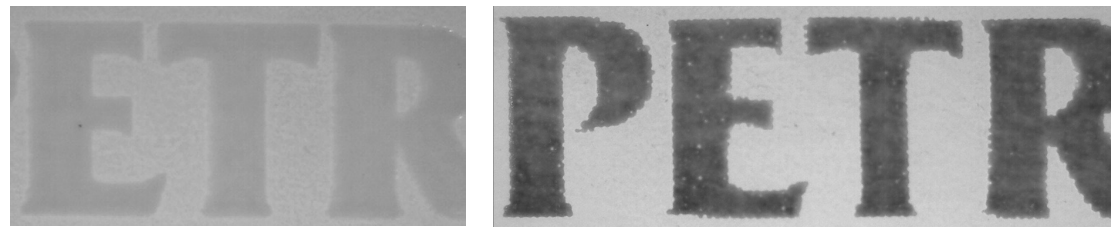

Figure 47. Thermochromic ink

21 Regula Forensics, https://regulaforensics.com/en/knowledge-hub/glossary-banknotes/ (accessed: 22.04.2018).

Nowa Kodyfikacja Prawa Karnego 49, 2018

(C) for this edition by $\mathrm{CNS}$ 


\section{Conclusion}

To conclude, security documents, like IDs, passports, and banknotes, are of different values, and usually of great value. They are widely used in daily life, and checking them is a must to avoid the negative consequences, represented by loss of money as well as infraction of security. This does not mean it needs highly-sophisticated instruments and well experienced, skilled experts, but rather by having basic information about inks and printing techniques, it is possible to check many security features, look at the document, feel it and tilt it, and that is sufficient. If this does not work, then use transmitted light, UV light, IR light, and a magnifier. In rare cases forensic laboratories and skilled experts have to be interfere.

Nevertheless, imposters may use genuine unforged documents for lookalike persons. If in any doubt that the document's verification is not right, then verification shall be focused on the person himself, his documents, and the history behind him (information), asking more questions, and observing behavioral reactions.

Moreover, special attention must be paid to the document holder's behavior, as imposters try to cover their anxiousness or psychological state in many ways. At checkpoints they cannot always circumvent this, by displaying suspicious behavior, such as exhibiting unusual nervousness or fidgeting, avoiding direct eye contact, standing back observing the officers, stepping back in line, displaying defensive body language, and rapidly blinking eyes.

\section{References}

Borota C.M., "Printing techniques used to secure border crossing documents", International Journal of Criminal Investigation 2, 2012, no. 1, pp. 31-40.

Funk M., Gillich E., Dörksen H., Lohweg V., Hofmann J., Türke T., Chassot D., Schaede J., "Intaglio quality measurement", Optical Document Security Conference, San Francisco, 10-12 February 2016.

Hollegie J., Basic Knowledge Document Recognition, Sdu, The Hague 2015.

Hollegie J., Inkten Presentation, Team Identity Fraud, Amsterdam 2018.

Huber R.A., "The latent image and its role in document security", Canadian Society of Forensic Science Journal 10, 1977, no. 4, pp. 127-134, DOI: 10.1080/00085030.1977.10756841.

Nowa Kodyfikacja Prawa Karnego 49, 2018

(C) for this edition by CNS 
Regula Forensics, https://regulaforensics.com/en/knowledge-hub/glossary-banknotes/ (accessed: 22.04.2018).

Regula Forensics, https://regulaforensics.com/en/knowledge-hub/glossary-documents/ (accessed: 22.04.2018).

\section{List of figures}

Figure 1. Offset colors are pastel soft and solid colors, as they are used for background printing; left: 20,000 Lebanese pounds; right: 1,000 Lebanese pounds; photographs by Saleh Mansour.

Figure 2. Offset printing always shows details, and micro-printing in negative and positive; left: Dino-Lite microscope image; right: passport specimen; left: ID Center, The Netherlands, 30.05.2011, materials from a document security training; right: photograph by Saleh Mansour.

Figure 3. Special unique security pattern printed in offset, Lebanese biometric passport; photograph by Saleh Mansour.

Figure 4. Guilloche and rainbow printing/IRIS; photograph by Saleh Mansour.

Figure 5. Lebanese biometric passport - invisible fluorescent ultraviolet ink, rainbow printing/IRIS; photograph by Saleh Mansour.

Figure 6. Infacio ${ }^{\circledR}$; J. Hollegie, Inkten Presentation, Team Identity Fraud, Amsterdam 2018.

Figure 7. See-through register - 10 Rufiyaa, Maldives; photograph by Saleh Mansour.

Figure 8. Photochromic ink; J. Hollegie, Inkten Presentation, Team Identity Fraud, Amsterdam 2018.

Figure 9. IR-fluorescent ink - 5,000 Serbian Dinar when exposed to infrared light; Regula Forensics, https://regulaforensics.com/en/knowledge-hub/glossary-banknotes/ (accessed: 22.04.2018).

Figure 10. Hidden multi-color; photograph by Saleh Mansour.

Figure 11. Fugitive ink; specimen from SICPA S.A.

Figure 12. Anti-Stokes ink, Poland, official passport when exposed to infrared light; Regula Forensics, https://regulaforensics.com/en/knowledge-hub/glossary-documents/ (accessed: 22.04.2018).

Figure 13. Forgery example. Dutch passport biodata page — inkjet background. Offset imitation; photograph by Saleh Mansour.

Figure 14. Forging example. Danish passport biodata page — inkjet background. Offset imitation; photograph by Saleh Mansour.

Figure 15. Forgery example. Syrian passport extension sticker; photograph by Saleh Mansour.

Figure 16. Forgery example. France - residence permit card, inkjet background. Offset imitation; photograph by Saleh Mansour.

Figure 17. Intaglio: (50,000 Lebanese pounds banknote) feathering, relief, Orlof, negative micro-text; photograph by Saleh Mansour. 
Figure 18. Schengen visa sticker: feathering, relief, Orlof, negative micro-text; photograph by Saleh Mansour.

Figure 19. Intaglio: feathering; photograph by Saleh Mansour.

Figure 20. Intaglio: micro-text negative printing; photograph by Saleh Mansour.

Figure 21. Intaglio: (20 Euro banknote) feathering, relief, Orlof, positive micro-text; photograph by Saleh Mansour.

Figure 22. Intaglio: Australian passport, Orlof; photograph by Saleh Mansour.

Figure 23. Montenegro official passport. Latent image KIPP, intaglio printing; Regula

Forensics, https://regulaforensics.com/en/knowledge-hub/glossary-documents/ (accessed: 28.02.2019).

Figure 24. Intaglio: micro-text, positive printing; photograph by Saleh Mansour.

Figure 25. IR metameric ink - intaglio printing when exposed to infrared light; Regula

Forensics, https://regulaforensics.com/en/knowledge-hub/glossary-banknotes/ (accessed: 22.04.2018).

Figure 26. Magnetic inks - 100 USA Dollar, 2006; Regula Forensics, https://regulaforensics.com/en/knowledge-hub/glossary-banknotes/ (accessed: 22.04.2018).

Figure 27. Intaglio Austrian passport; photograph by Saleh Mansour.

Figure 28. Intaglio imitation; J. Hollegie, Basic Knowledge Document Recognition, Sdu,

The Hague 2015, p. 129.

Figure 29. Intaglio Turkish transit visa sticker; photograph by Saleh Mansour.

Figure 30. Intaglio imitation; photograph by Saleh Mansour.

Figure 31. Letterpress - beaded edges, printing interruptions; photograph by Saleh Mansour.

Figure 32. Letterpress - 5,000 Lebanese pounds. Beaded edges, printing interruptions; photograph by Saleh Mansour.

Figure 33. Letterpress - embossing effect on the rear side; photograph by Saleh Mansour.

Figure 34. Letterpress: Hungarian passport, bleeding ink; Regula Forensics, https://regulaforensics.com/en/knowledge-hub/glossary-documents/ (accessed: 28.02.2019).

Figure 35. Multi-colored serial number; Regula Forensics, https://regulaforensics.com/ en/knowledge-hub/glossary-banknotes/ (accessed: 22.04.2018).

Figure 36. Letterpress - forged example (inkjet V/S letterpress and offset); Dino-Lite microscope image; ID Center, The Netherlands, 30.05.2011; materials from a document security training.

Figure 37. Silkscreen printing — tooth edges, Slovakia, travel document; Regula Forensics, https://regulaforensics.com/en/knowledge-hub/glossary-documents/ (accessed: 28.02.2019).

Figure 38. Silkscreen printing — new Lebanese passport - OVI; photograph by Saleh Mansour.

Figure 39. SPARK, OVMI — silkscreen printing; photograph by Saleh Mansour.

Figure 40. OVI silkscreen printing — Czech passport; Regula Forensics, https://regulaforensics.com/en/knowledge-hub/glossary-documents/ (accessed: 28.02.2019).

Figure 41. Conductive ink - silkscreen printing; photograph by Saleh Mansour; from brochure from the company Petrel Security, ref. 44030. 
Figure 42. Metameric inks pair - Japanese passport; Regula Forensics, https://regulaforensics.com/en/knowledge-hub/glossary-documents/ (accessed: 22.04.2018).

Figure 43. Thermal ink - 500 Latvian Lats, 2008; Regula Forensics, https://regulaforensics.com/en/knowledge-hub/glossary-banknotes/ (accessed: 22.04.2018).

Figure 44. Metallic ink; Regula Forensics, https://regulaforensics.com/en/knowledge-hub/ glossary-banknotes/ (accessed: 22.04.2018).

Figure 45. Metallic inks - Estonian passport; Regula Forensics, https://regulaforensics. com/en/knowledge-hub/glossary-documents/ (accessed: 22.04.2018).

Figure 46. Conductive ink - chip antenna; materials from a BM.I printing inks presentation from a document security training, Beirut 2017.

Figure 47. Thermochromic ink; photograph by Saleh Mansour; from brochure from the company Petrel Security, ref. 56055.

\section{Summary}

Security documents are valuable documents protected by a mixture of security features, starting from security paper, inks, printing techniques, and additional security properties. However, this article will discuss the main security features, supported by genuine and forged examples, to demonstrate the most frequent modern use of security features to protect valuable documents, and giving useful hints to detect forgeries and imposters as well.

Keywords: security documents, security inks, printing techniques, forged documents, security features, offset printing, letterpress, intaglio, silkscreen. 